\title{
Intraspecific Antagonism in Natural Populations of Wood-decaying Basidiomycetes
}

\author{
By A. D. M. RAYNER AND N. K. TODD \\ Department of Biological Sciences, University of Exeter, \\ Prince of Wales Road, Exeter EX4 4 PS
}

(Received I5 March 1977 ; revised 25 May 1977)

\begin{abstract}
Wood undergoing decay by a variety of white-rotting Basidiomycetes often contains narrow, dark, relatively undecayed zones separating decayed regions. Isolates derived from either side of such zones, although often of the same fungal species, are frequently antagonistic.

Methods are described for investigating the genetic basis and significance of such intraspecific antagonism in natural populations of decay fungi within individual stumps and logs. Results obtained for Coriolus versicolor show that decaying wood occupied by this fungus often contains populations of individual mutually antagonistic dikaryons, the monokaryotic components of which are often completely interfertile. These and similar results for other fungi suggest a fundamental departure from the concept of the unit mycelium.
\end{abstract}

\section{INTRODUCTION}

It is often assumed that when genetically distinct mycelia of the same fungus species meet within a substrate, they will fuse to form a mycelium acting ecologically and physiologically as a unit, though genetically a mosaic. Evidence that this may occur in nature has been provided by the classic study of Buller (193I) with Coprinus sterquilinus Fr. and by Burnett \& Partington (1957) with Coriolus versicolor (L. ex Fr.) Quél. [Polystictus versicolor (L.) Fr.] and Piptoporus betulinus (Bull. ex Fr.) Karst. With C. versicolor, a tetrapolar species, Burnett and Partington showed that adjacent fruit bodies on a stump contained different permutations and combinations of the same mating-type factors. They did not, however, investigate the detailed structure of the mycelium within the wood.

The existence of antagonistic influences between genetically distinct mycelia of the same species may militate against formation of the unit mycelium. This antagonism has been observed as so-called 'barrages' or 'demarcation zones' between colonies placed opposite each other in culture. Commonly this occurs between monokaryons and results from either homo- or heterogenic incompatibility (Raper, I966; Esser \& Blaich, 1973). In a few cases, antagonism has also been observed between dikaryons where heterogenic incompatibility may also be implicated (Adams \& Roth, I967; Mounce, 1929; Campbell, I938; Barrett \& Uscuplic, I97I). The latter has only been demonstrated in culture, frequently between geographically separated isolates. The operation of intraspecific antagonism, within the natural substrate, does not appear to have been demonstrated convincingly.

Recently, however, Rayner (I976) has shown that white-rotted wood occupied by, for example, Bjerkandera adusta (Willd. ex Fr.) Karst., C. versicolor, Stereum hirsutum (Willd. ex Fr.) S. F. Gray and Phlebia merismoides Fr. often contains networks of narrow, dark, relatively undecayed zones which are frequently occupied by various dematiaceous Hyphomycetes especially Rhinocladiella spp. In logs colonized extensively by $C$. versicolor or $S$. hirsutum it was shown that isolates derived from different sides of the dark zones, although similar morphologically and with clamp-connexions, were antagonistic, both on $3 \%$ malt 

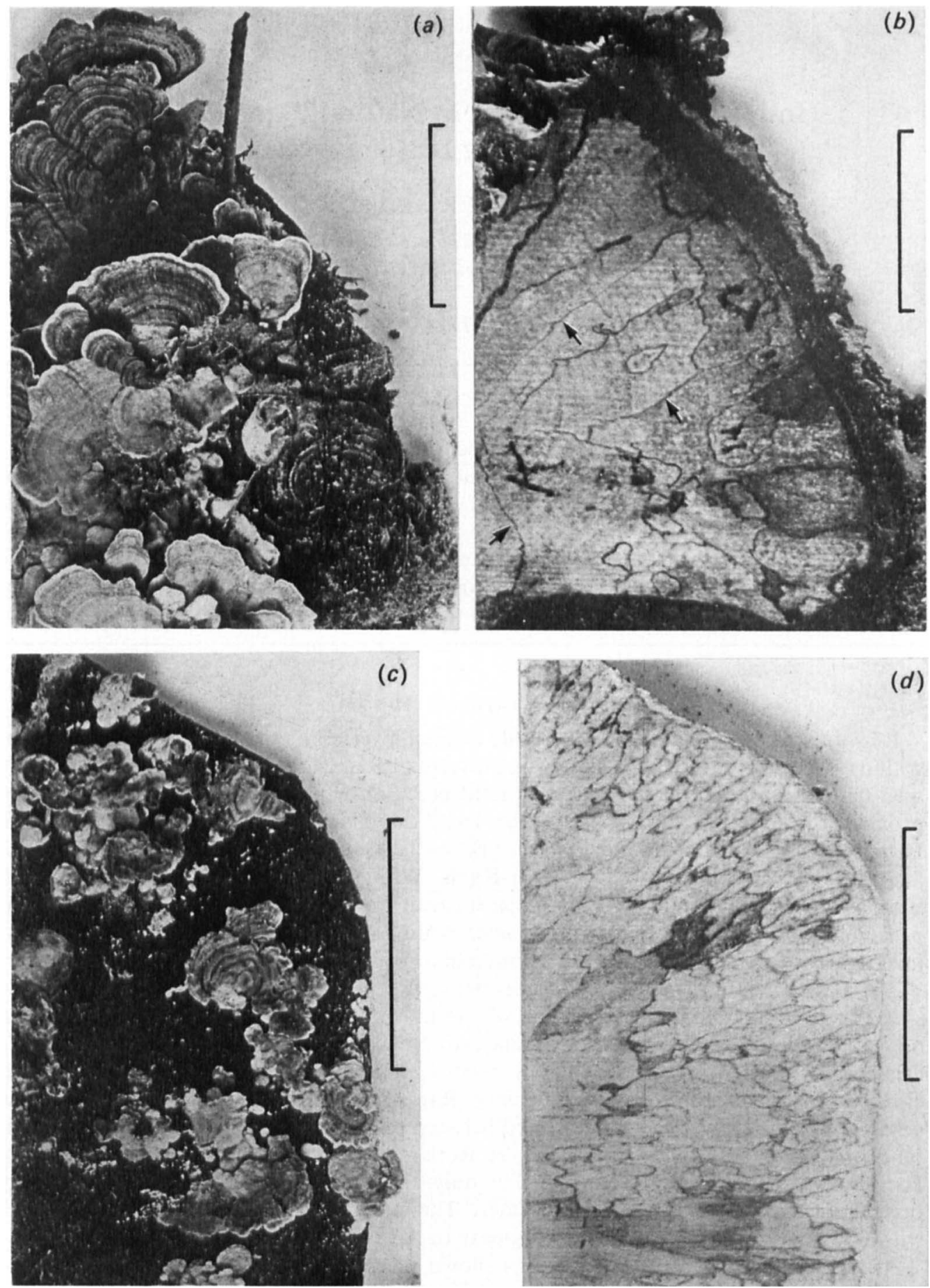

Fig. I. Surface and underlying wood of portions of birch stumps colonized by C. versicolor. (a) Surface with numerous, large polymorphic fruit bodies; $(b)$ underlying wood with large bleached decay regions separated by narrow dark interaction zones (arrowed); $(c)$ surface with numerous, but small and stunted fruit bodies; $(d)$ underlying wood with numerous small decay regions separated by a fine network of dark interaction zones. All bar markers represent $5 \mathrm{~cm}$. 


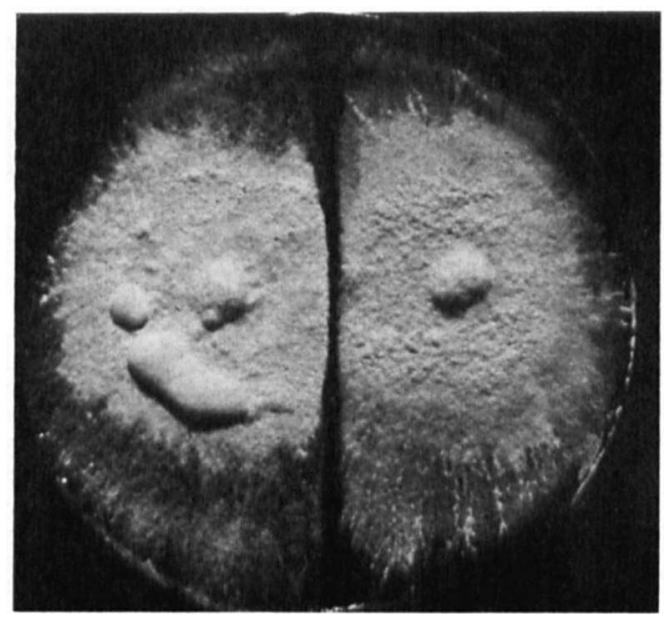

Fig. 2. Pairing between isolates of $C$. versicolor from adjacent decay regions, showing formation of a narrow pigmented interaction zone.

agar and on incubated wood sections. On agar the antagonism involved the development of discrete narrow demarcation zones, at first clear but later often containing pigment (various shades of yellow with $S$. hirsutum, and sepia with $C$. versicolor).

The genetic basis and significance of intraspecific antagonism in delimiting separate individual mycelia of several common wood-decaying Basidiomycetes is now being investigated by analysis of the three-dimensional structure of natural populations within individual stumps and logs. This communication describes preliminary results obtained with C. versicolor.

\section{METHODS}

The projecting portions of birch (Betula L. spp.) stumps bearing polymorphic collections of fruit bodies of C. versicolor (e.g. Fig. I $a$ ) were collected from the field and sawn into about $2 \mathrm{~cm}$ thick transverse sections. At this stage longitudinally continuous decay regions separated by narrow dark zones were normally detectable in the wood (e.g. Fig. $\mathrm{x} b$ ) and their position correlated with that of the fruit bodies on the surface. Isolations of $C$. versicolor from each decay region were then made as follows.

(i) From the wood: fragments of wood were removed from different levels in the stump and after surfacesterilization in $10 \%(\mathrm{v} / \mathrm{v})$ sodium hypochlorite they were placed on $3 \%(\mathrm{w} / \mathrm{v})$ malt agar containing $0.70 \%$ (w/v) crystamycin and incubated at $25^{\circ} \mathrm{C}$. Subcultures were prepared as soon as sufficient mycelium had grown out.

(ii) From basidiospores: fruit bodies were placed in Petri dishes at $10{ }^{\circ} \mathrm{C}$ and allowed to deposit spores. The spores were suspended in sterile distilled water and plated out at low density on $3 \%$ malt agar containing crystamycin and incubated overnight at $25{ }^{\circ} \mathrm{C}$. Germinated spores were isolated on $3 \%$ malt agar using a fine wire.

(iii) From fruit body tissue: the fruit bodies used for basidiospore isolation were torn to expose a fresh sterile surface from which tissue was isolated on to $3 \%$ malt agar containing crystamycin and incubated at $25^{\circ} \mathrm{C}$. Subcultures were established from new mycelial growth.

The isolates were paired in various combinations on $3 \%$ malt agar and incubated at $25{ }^{\circ} \mathrm{C}$. In addition, dedikaryotization of certain isolates was attempted using the method of Miles \& Raper (1956).

\section{RESULTS AND DISCUSSION}

Whilst several different stumps were analysed, for the sake of simplicity, detailed results will only be given for one particular example.

From Table I it can be seen that when wood or fruit body tissue isolates (which were dikaryotic) obtained from different decay regions were paired, antagonism was invariably 


\section{Table I. Pairings between wood and fruit body tissue isolates from different decay regions in a stump}

Letters indicate the decay region, and numbers $\mathrm{I}$ and 2 refer to different levels within a decay region. $O$, Antagonism; $\triangle$, antagonism accompanied by pigment production; $\boldsymbol{O}$, complete fusion of isolates.

(a) Pairings between wood isolates

$$
Y_{2} \mathrm{XI}_{I} \text { OI NI LI JI HI GI CI AI }
$$

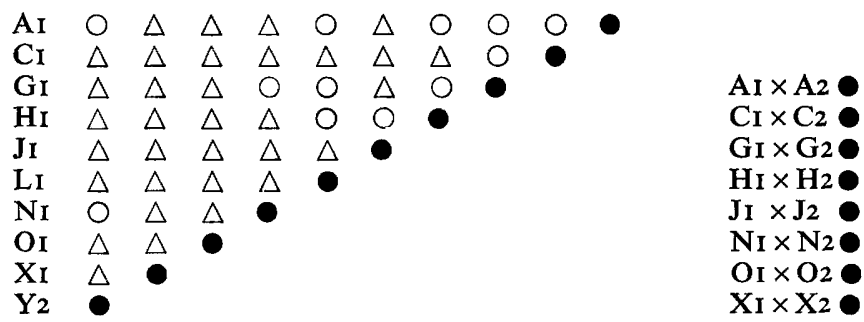

(b) Pairings between fruit body isolates

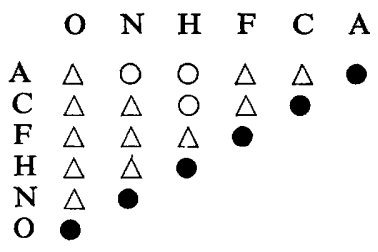

(c) Pairings between fruit body and wood isolates

fruit body wood

\begin{tabular}{|c|c|c|}
\hline $\mathbf{A}$ & $x$ & AI \\
\hline C & $x$ & CI \\
\hline $\mathbf{H}$ & $x$ & HI \\
\hline $\mathrm{O}$ & $x$ & $\mathrm{OI}_{\mathrm{I}}$ \\
\hline $\mathbf{N}$ & $x$ & $N_{I}$ \\
\hline A & $x$ & $\mathbf{J}_{\mathbf{I}}$ \\
\hline C & $x$ & Or \\
\hline $\mathrm{H}$ & $x$ & $\mathbf{J}_{\mathbf{I}}$ \\
\hline $\mathrm{O}$ & $x$ & $\mathrm{~N}_{\mathrm{I}}$ \\
\hline
\end{tabular}

observed (Fig. 2). In pairings between isolates from the same decay region, the colonies merged imperceptibly regardless of their origin from fruit body tissue or different levels within the wood. (Identical findings have recently been obtained with $S$. hirsutum.)

Matings between a large number of monokaryotic basidiospore isolates from the same fruit body indicated tetrapolar incompatibility as expected from previous work (e.g. Burnett \& Partington, I957). In many pairings, clear demarcation zones developed, but these differed from those observed between dikaryons, usually being broader and rarely accompanied by pigment production. Ten-by-ten matrices were then constructed to obtain tester strains of known mating type for fruit bodies from each decay region. The tester strains derived from fruit bodies from each of several adjacent decay regions were paired in all possible combinations. The results obtained are given in Table 2 . In the majority of pairings, isolates derived from different zones were fully compatible. This confirmed the intraspecific nature of the antagonism and implies that the different decay regions contained mycelia with different mating-type factors, although isolates from $\mathrm{N}$ and $\mathrm{F}$ and $\mathrm{F}$ and $\mathrm{C}$ probably have at least one mating-type factor in common.

These results suggest that the decay regions contained mutually antagonistic dikaryotic mycelia, whose respective monokaryons were interfertile. That the antagonism may be regarded as a mainly dikaryotic phenomenon was shown by pairing synthesized dikaryons from compatible monokaryons derived from fruit bodies from each decay region (Table 3 ). The results given in Table 3 show that antagonism was expressed between such dikaryons, even when their respective monokaryons had been shown to be fully interfertile (Table 2).

It remains to discuss the degree to which the mycelia in separate decay regions were distinct from each other and genetically uniform. That each mycelium was distinct 
Table 2. Compatibility of monokaryotic tester strains of each mating type from different decay regions

Letters indicate the decay region and numbers are isolate numbers. +, Clamps formed; - , clamps not formed.

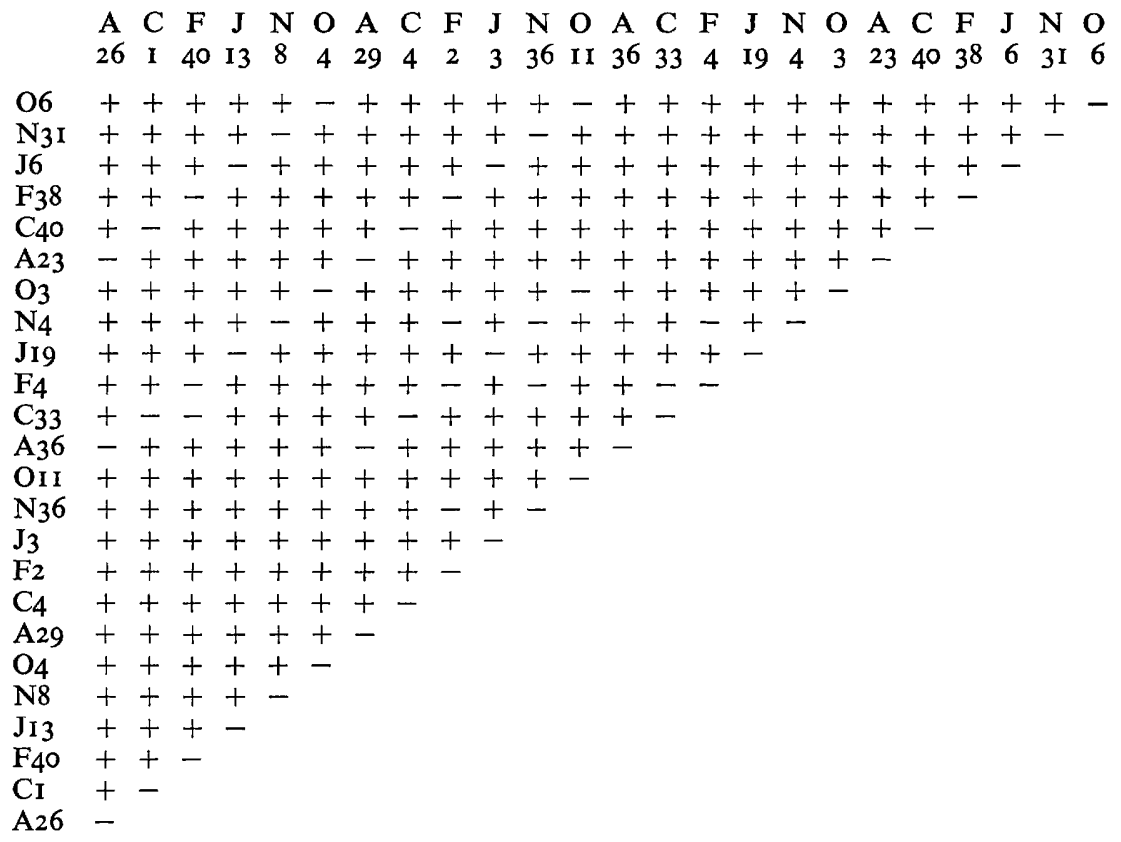

Table 3. Pairings between dikaryons synthesized from basidiospore isolates of known mating type

Symbols and codes are as in Tables 1 and 2 respectively.

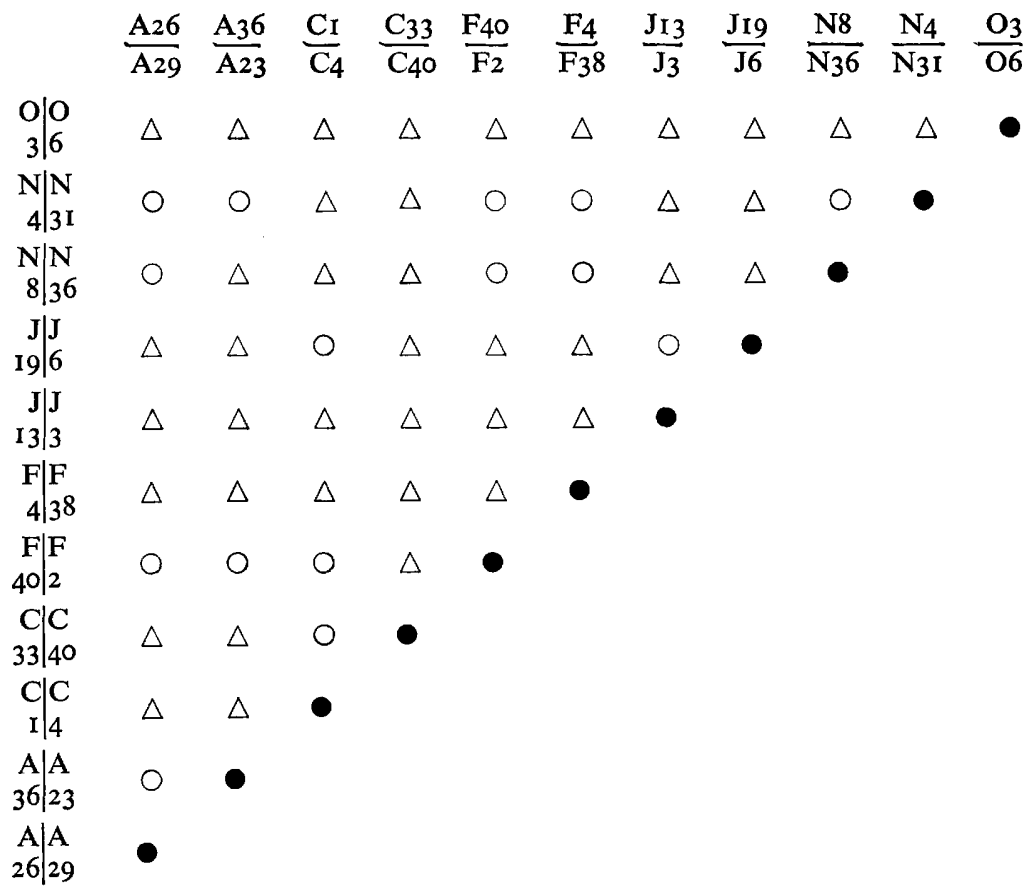


Table 4. Number of compatible pairings between samples of monokaryons derived by dedikaryotization of wood isolates, and tester strains

Codes are as in Tables $I$ and 2.

\begin{tabular}{|c|c|c|c|c|c|c|c|c|c|}
\hline \multirow{2}{*}{$\begin{array}{c}\text { Dedikaryotized } \\
\text { isolates }\end{array}$} & \multirow{2}{*}{$\begin{array}{c}\text { Total no, of } \\
\text { derived } \\
\text { monokaryons } \\
\text { tested }\end{array}$} & \multicolumn{8}{|c|}{ Tester strains } \\
\hline & & $\mathrm{O}_{3}$ & $\mathrm{O}_{4}$ & O6 & OI I & N8 & $N_{36}$ & $\mathrm{~N}_{4}$ & $\mathrm{~N}_{3} \mathrm{I}$ \\
\hline Or & IO & 0 & 0 & 0 & ro & - & - & - & - \\
\hline $\mathrm{O}_{2}$ & IO & 0 & 0 & 0 & IO & - & - & - & - \\
\hline $\mathrm{NI}_{\mathrm{I}}$ & 8 & - & - & - & - & 0 & 0 & 0 & 8 \\
\hline $\mathrm{N}_{2}$ & 9 & - & - & - & - & 0 & 0 & 0 & 9 \\
\hline
\end{tabular}

physiologically and ecologically was indicated by the presence of the narrow dark interaction zones between decay regions. Supporting evidence has been provided by observing, in a range of woody substrata, that where the spacing between the interaction zones was large, and the amount of wood occupied by each individual correspondingly great, numerous sizeable fruit bodies are frequently present (Fig. I $a$ and $b$ ). Conversely, when the spacing is small, numerous but very much smaller and stunted fruit bodies occur (Fig. I $c$ and $d$ ).

Three lines of evidence indicate the genetic uniformity of the mycelia within each decay region. First, whilst there was considerable variation between fruit bodies corresponding to different decay regions, those from the same region appeared identical. Secondly, it was demonstrated that different fruit bodies within the same decay region contained the same mating-type factors. Final supporting evidence has been provided by preliminary results from dedikaryotization experiments (Table 4). These have shown that monokaryotic mycelia derived from wood isolates from different levels in the same decay region all contain nuclei bearing the same mating-type factors. It is of interest that these experiments should have resulted in the selection of only one nuclear type, and this phenomenon requires further investigation. Nevertheless this result, combined with the other observations, strongly supports the view that each individual mycelium consists of a single dikaryon, although this would seem to contradict the results of Burnett \& Partington (1957).

In summary, these findings suggest that decaying wood occupied by a single fungus species may often contain populations of mutually antagonistic individual mycelia, rather than a single genetically heterogeneous mycelium, as has been previously supposed. Further work may demonstrate this feature to be widespread, even amongst the fungi as a whole.

\section{REFERENCES}

AdAms, D. H. \& Roth, L. F. (1967). Demarcation lines in paired cultures of Fomes cajanderi as a basis for detecting genetically distinct mycelia. Canadian Journal of Botany 45, I583-1589.

BARRETT, D. K. \& Uscuplic, M. (197I). The field distribution of interacting strains of Polyporus schweinitzii and their origin. New Phytologist 7o, $581-598$.

Buller, A. H. R. (193I), Researches in Fungi IV. London: Longmans Green.

Burnett, J. H. \& Partington, M. (1957). Spatial distribution of fungal mating-type factors. Proceedings of the Royal Physical Society of Edinburgh 26, 6I-68.

CAMPBELl, A. H. (1938). Contribution to the biology of Collybia radicata (Relh.) Berk. Transactions of the British Mycological Society 22, I5I-I 59.
EsSER, K. \& BlaICH, R. (I973). Heterogenic incompatibility in plants and animals. Advances in Genetics 17, 107-152.

Miles, P. G. \& RAPER, J. R. (1956). Recovery of the component strains from dikaryotic mycelia. Mycologia 48, 484-494.

Mounce, I. (r929). Studies in forest pathology. II. The biology of Fomes pinicola (Sw.) Cooke. Bulletin of the Canadian Department of Agriculture No. I I I, New Series.

RAPER, J. R. (1966). Genetics of Sexuality in Higher Fungi. New York: Ronald Press.

RAYNER, A. D. M. (1976). Dematiaceous hyphomycetes and narrow dark zones in decaying wood. Transactions of the British Mycological Society 67 , $546-549$. 